\title{
Development and Validation of a Practical Two-Step Prediction Model and Clinical Risk Score for Post- Thrombotic Syndrome
}

Citation for published version (APA):

Amin, E. E., van Kuijk, S. M. J., Joore, M. A., Prandoni, P., ten Cate, H., \& ten Cate-Hoek, A. J. (2018). Development and Validation of a Practical Two-Step Prediction Model and Clinical Risk Score for PostThrombotic Syndrome. Thrombosis and Haemostasis, 118(7), 1242-1249. https://doi.org/10.1055/s-00381655743

Document status and date:

Published: 01/07/2018

DOI:

10.1055/s-0038-1655743

Document Version:

Publisher's PDF, also known as Version of record

Document license:

Taverne

Please check the document version of this publication:

- A submitted manuscript is the version of the article upon submission and before peer-review. There can be important differences between the submitted version and the official published version of record.

People interested in the research are advised to contact the author for the final version of the publication, or visit the DOI to the publisher's website.

- The final author version and the galley proof are versions of the publication after peer review.

- The final published version features the final layout of the paper including the volume, issue and page numbers.

Link to publication

\footnotetext{
General rights rights.

- You may freely distribute the URL identifying the publication in the public portal. please follow below link for the End User Agreement:

www.umlib.nl/taverne-license

Take down policy

If you believe that this document breaches copyright please contact us at:

repository@maastrichtuniversity.nl

providing details and we will investigate your claim.
}

Copyright and moral rights for the publications made accessible in the public portal are retained by the authors and/or other copyright owners and it is a condition of accessing publications that users recognise and abide by the legal requirements associated with these

- Users may download and print one copy of any publication from the public portal for the purpose of private study or research.

- You may not further distribute the material or use it for any profit-making activity or commercial gain

If the publication is distributed under the terms of Article $25 \mathrm{fa}$ of the Dutch Copyright Act, indicated by the "Taverne" license above, 


\title{
Development and Validation of a Practical Two-Step Prediction Model and Clinical Risk Score for Post-Thrombotic Syndrome
}

\author{
Elham E. Amin ${ }^{1,2}$ Sander M. J. van Kuijk ${ }^{2}$ Manuela A. Joore ${ }^{2}$ Paolo Prandoni ${ }^{3}$ Hugo ten Cate ${ }^{1,4}$ \\ Arina J. ten Cate-Hoek ${ }^{1,4}$ \\ ${ }^{1}$ Department of Internal Medicine, Maastricht University \\ Medical Centre, Maastricht, The Netherlands \\ 2 Department of Clinical Epidemiology and Medical Technology \\ Assessment, School for Public Health and Primary Care, Maastricht \\ 6200 MD, Maastricht, The Netherlands \\ University, Maastricht, The Netherlands \\ ${ }^{3}$ Arianna Foundation on Anticoagulation, Bologna, Italy \\ ${ }^{4}$ Department of Biochemistry, Cardiovascular Research \\ Institute Maastricht, Maastricht University, Maastricht, \\ The Netherlands \\ Thromb Haemost 2018;118:1242-1249.
}

\begin{abstract}
Keywords

- post-thrombotic syndrome

- clinical risk score

- prediction model

- deep vein thrombosis

- validation

Background Post-thrombotic syndrome (PTS) is a common chronic consequence of deep vein thrombosis that affects the quality of life and is associated with substantial costs. In clinical practice, it is not possible to predict the individual patient risk. We develop and validate a practical two-step prediction tool for PTS in the acute and subacute phase of deep vein thrombosis.

Methods Multivariable regression modelling with data from two prospective cohorts in which 479 (derivation) and 1,107 (validation) consecutive patients with objectively confirmed deep vein thrombosis of the leg, from thrombosis outpatient clinic of Maastricht University Medical Centre, the Netherlands (derivation) and Padua University hospital in Italy (validation), were included. PTS was defined as a Villalta score of $\geq 5$ at least 6 months after acute thrombosis.

Results Variables in the baseline model in the acute phase were: age, body mass index, sex, varicose veins, history of venous thrombosis, smoking status, provoked thrombosis and thrombus location. For the secondary model, the additional variable was residual vein obstruction. Optimism-corrected area under the receiver operating characteristic curves (AUCs) were 0.71 for the baseline model and 0.60 for the secondary model. Calibration plots showed well-calibrated predictions. External validation of the derived clinical risk scores was successful: AUC, 0.66 (95\% confidence interval [Cl], 0.63-0.70) and $0.64(95 \% \mathrm{Cl}, 0.60-0.69)$.

Conclusion Individual risk for PTS in the acute phase of deep vein thrombosis can be predicted based on readily accessible baseline clinical and demographic characteristics. The individual risk in the sub-acute phase can be predicted with limited additional clinical characteristics.
\end{abstract}

received

January 24, 2018

accepted after revision

April 12, 2018 (c) 2018 Georg Thieme Verlag KG Stuttgart · New York
DOI https://doi.org/

$10.1055 / \mathrm{s}-0038-1655743$. ISSN 0340-6245. 


\section{Introduction}

Post-thrombotic syndrome (PTS) is a chronic condition that develops in 25 to $50 \%$ of the patients after deep vein thrombosis (DVT) of the leg. ${ }^{1,2}$ It is a compilation of signs and symptoms varying from pain and oedema to venous ulcerations. The presence of (severe) PTS is associated with threefold higher medical and total costs compared with DVT in the absence of PTS. ${ }^{3,4}$ Moreover, quality of life declines as PTS becomes worse. ${ }^{1,2}$ Although the exact pathophysiology of the condition is not fully understood, several modifiable and nonmodifiable risk factors have previously been identified as established or potential predictors: (ipsilateral) DVT recurrence, ${ }^{2,5}$ poor regulation of international normalized ratio (INR), ${ }^{6,7}$ proximal DVT, ${ }^{3,8,9}$ higher body mass index, ${ }^{8,10}$ presence of varicose veins, ${ }^{9,11}$ presence of residual vein obstruction, ${ }^{3,12}$ older age, ${ }^{5,9}$ gender, ${ }^{8}$ elevated levels of biomarkers such as C-reactive protein (CRP), D-dimer, factor VIII (FVIII), interleukin (IL)-6, IL8 and intercellular adhesion molecule 1 (ICAM-1), ${ }^{13-15}$ and type and quality of anticoagulant prescribed. ${ }^{6,7,16}$ Thus far, however, it is not possible in clinical practice to combine these factors and predict the risk of PTS despite the need to identify patients at high risk.

One of the most important hurdles for development of a prediction model for PTS is the absence of a gold standard for the diagnosis. The diagnosis is based on one of the several clinical scores that have been developed over the years. ${ }^{17-19}$ In 2008, the International Society for Thrombosis and Haemostasis (ISTH) Subcommittee for Standardization recommended the Villalta score as the preferred clinical score. ${ }^{18}$

In the absence of effective therapies for PTS preventive measures remain warranted. To this end, elastic compression stockings are widely applied and although the effectiveness has been disputed, a recent meta-analysis showed a 30\% reduction in occurrence of PTS achieved by compression stockings. ${ }^{20}$ In addition, other measures such as physical activity, lymphatic drainage, the use of venous-return assist devices and veno-active drugs that were found to enhance the efficacy of compression therapy in patients with PTS, might if initiated at an earlier point in time in selected patients, potentially prevent PTS. ${ }^{12,21-24}$ Moreover, in patients with highest risk of PTS catheter-directed thrombolysis might be considered. ${ }^{25,26}$ If the individual risk of patients is known, treatment can be personalized and hence expected to be more efficient. We therefore developed and externally validated a two-step prediction model for PTS and derived simplified clinical risk scores that could serve as a tool for identification of patients at increased risk of PTS, as well as for better targeting of therapy. Additionally, we externally validated the clinical risk scores.

\section{Methods}

\section{Derivation Cohort}

For the development of the two-step prediction model, data from a prospective DVT cohort were used. Data were collected from June 2003 until June 2013. This cohort was part of medical care evaluation in a clinical care pathway within the Maastricht University Medical Center+ in the Netherlands (medical ethical approval registration number 15-4256) and was comprised of adult patients who were followed up for 2 years after DVT had been objectively confirmed. There were no exclusion criteria. A medical doctor assessed the signs and symptoms of PTS using the Villalta score at 3, 6, 12 and 24 months post-DVT. Baseline measurements (first office visit within 2-3 weeks following acute presentation and treatment for thrombosis) included: height, weight, medical history, current health status, presence of venous insufficiency, hypertension, smoking status, family history for thrombosis and appraisal of the triggering factors for DVT such as immobilization, surgery, oral contraceptive use or presence of malignancy. Follow-up measurements included: assessment of residual vein obstruction when discontinuation of anticoagulation was considered, and plasma levels of D-dimer, levels of FVIII and CRP. All patients received anticoagulation treatment for a minimum of 3 months and compression therapy for at least 6 months.

\section{Sample Size}

The occurrence of PTS is between 20 and 50\%. A conservative percentage of $35 \%$ was chosen for the sample size calculation. We followed the suggested sample size calculation for logistic regression, ${ }^{27}$ where $p$ is the smallest of the proportions of negative or positive cases in the population and $k$ is the number of covariates (the number of independent variables), then the minimum number of cases to include is: $N=10 \mathrm{k} / \mathrm{p}$. We had 12 covariates to include in the model and the proportion of positive cases in the population is approximately 0.35 (35\%). The minimum number of cases required is therefore $N=10 \times 12 / 0.35=343$. This would implicate that a cohort of 343 patients is required for our 12-candidate predictors.

\section{Outcome Measure}

The outcome was PTS defined as a single Villalta score of $\geq 5$ as of 6 months after diagnosis of DVT. The Villalta score is comprised of several items of leg complaints and/or objectively confirmable signs. The items include pain, cramps, heaviness, itching, tingling, oedema, redness, skin indurations, hyperpigmentation, venectasia, pain on calf compression and, in the most severe cases, venous ulcerations. Depending on the severity, each item is scored on a 4-point scale. The presence or history of a venous ulcer is scored as 33 points. $^{28}$

\section{Candidate Predictors}

As candidate predictors, we included predictors that are reported in the literature except for IL-6 and -8, ICAM-1 and type of anticoagulant because data on these predictors were not available from the derivation cohort. We also included type of DVT (provoked) as a candidate predictor.

\section{Model Development}

We developed a two-step model consisting of a model to be applied at baseline to predict the probability of developing 
PTS at 6 months, and a model to be applied at 6 months to predict the probability of PTS 24 months after initial thrombosis for those patients who did not develop PTS till then. The first model included only baseline demographics and clinical characteristics. The second model was similar to the baseline model with the addition of the following potential predictor variables: levels of plasma biomarkers such as D-dimer, FVIII and CRP, INR regulation during the first 3 months following acute DVT and presence of residual vein obstruction. Incomplete data were completed based on medical records if possible.

Multiple imputation was used to impute the incomplete records, since using only complete records may cause a considerable loss of precision and is more likely to bias results. ${ }^{29}$ Sensitivity analysis was performed to exclude significant differences between results of the imputed and the original data. Variable selection in the final models was performed using backward stepwise elimination in multivariable logistic regression analysis. A p-value of 0.3 was chosen for excluding variables from the model so that potentially important predictors were not erroneously deleted. ${ }^{30}$

First, all analyses were performed with continuous variables as such. To develop simple and practical models, continuous variables were subsequently dichotomized based on cut-off values derived from literature or, if no information was available, based on the data. Models with and without the addition of biomarkers were assessed. The discriminative ability of the models was expressed as the magnitude of the area under the receiver operating characteristic curve (AUC). The ability of the models (baseline model and secondary model) to generate predicted probabilities comparable to observed outcome frequencies was determined by visually assessing the calibration curves. The analyses were performed using SPSS version 23. R version 3.1.3 was used to perform the internal validation of the models and to obtain calibration plots. The predictive performance of the models was explored. Based on the regression coefficients of the models a practical clinical score was estimated. These clinical scores for the baseline and secondary models were externally validated.

\section{Internal Validation}

To internally validate the two-step model, we used bootstrapping techniques. ${ }^{30}$ We drew 1,000 bootstrap samples from the original dataset and re-estimated the model on each sample. The average differences in performance measures of those models on the bootstrap sample and the original data are estimators of optimism in the model performance. We subtracted the measures of optimism from the initial performance measures (i.e. AUC) to obtain optimism-corrected measures of performance. In addition, we computed a shrinkage factor. The regression coefficients were subsequently multiplied by this shrinkage factor. These shrunk coefficients combined with a re-estimated intercept render future predictions less extreme, and counteract the effect of over-fitting a prediction model. The individual probability estimation for patients can be performed using the following equation: Probability $=1 /(1+\exp (-\mathrm{LP})$, in which LP is the linear combination of the intercept and all coefficients multiplied by their respective patient values.

\section{External Validation}

The validation cohort consisted of 1,107 adult patients from Padua University Hospital outpatient clinic in Italy who were diagnosed with proximal DVT of the leg. Exclusion criteria were: history of ipsilateral DVT less than 2 years ago, thrombectomy, arterial thrombotic events, active cancers, deficiencies in natural anticoagulants or medical conditions leading to prolonged immobilization. All patients received anticoagulation. The duration of anticoagulation depended on international guidelines, patients' preferences and risk profile. All patients received compression therapy for at least 6 months. PTS was assessed at 3, 6, 12, 18 and 24 months after DVT diagnosis. Three months after DVT compression, ultrasonography was performed to determine the presence of residual thrombosis. All variables of the original model except for smoking status were present in the validation cohort. There were no missing values for the available variables. Model performance was quantified as the AUC. Because we validated clinical risk scores derived from the prediction models, calibration would not have additional value as the resulting scores do not reflect probabilities. External validation was performed with SPSS version 23 .

\section{Reporting}

This study adhered to the Transparent Reporting of a multivariable prediction model for Individual Prognosis or Diagnosis (TRIPOD) (-Supplementary Material, available in the online version) statement for reporting. ${ }^{31}$

\section{Results}

The derivation cohort consisted of 479 patients of whom 28 were eventually excluded from the analysis due to large amount of missing information on follow-up visits. All 1,107 patients in the validation cohort were included in the analyses. - Table 1 shows the baseline demographic and clinical characteristics of both study populations.

In the derivation cohort, at 6 months after DVT $22.8 \%$ developed PTS. Of the remaining patients who did not develop PTS until 6 months post-DVT, 29.6\% developed PTS in the 18 months following the initial period of 6 months. At the end of the 24 months' follow-up, $45.7 \%$ of the entire cohort was diagnosed with PTS.

\section{Model Development}

-Table 2 illustrates the final reduced prediction models with the dichotomized predictors based on backward elimination, before and after internal validation. The bootstrapping procedure yielded shrinkage factors between 0.81 and 0.86 .

\section{Model Performance}

The discriminative ability of the models is represented as the AUC. The AUCs for the baseline model followed by 
Table 1 Baseline and clinical characteristics of the study populations

\begin{tabular}{|l|l|l|}
\hline & $\begin{array}{l}\text { Derivation } \\
\text { cohort } \\
N=451\end{array}$ & $\begin{array}{l}\text { Validation } \\
\text { cohort } \\
N=1,107\end{array}$ \\
\hline Characteristic & $239(53.0)$ & $726(65.6)$ \\
\hline Age $>56, n(\%)$ & $228(50.6)$ & $545(49.2)$ \\
\hline Male sex, $n(\%)$ & $103(22.8)$ & Unknown \\
\hline Smoker, $n(\%)$ & $67(14.9)$ & $355(32.1)$ \\
\hline $\begin{array}{l}\text { Varicose veins, } \\
n(\%)\end{array}$ & $132(29.3)$ & $127(11.5)$ \\
\hline $\begin{array}{l}\text { Body mass index }>30, \\
n(\%)\end{array}$ & $91(20.2)$ & $164(14.8)$ \\
\hline $\begin{array}{l}\text { Previous deep vein } \\
\text { thrombosis, } n \text { (\%) }\end{array}$ & $242(53.7)$ & $526(47.5)$ \\
\hline $\begin{array}{l}\text { Provoked thrombosis, } \\
n(\%)\end{array}$ & $220(48.8)$ & $585(52.8)$ \\
\hline $\begin{array}{l}\text { lliofemoral thrombosis, } \\
n(\%)\end{array}$ & 20 \\
\hline
\end{tabular}

the secondary model were 0.71 and 0.60 after internal validation. Sensitivity analysis showed no difference in model performance between using only complete cases and the imputed data.

The differences between the baseline models based on continuous and dichotomized variables were negligible. For the secondary model the differences were also small, the highest values of AUC (0.67, 95\% confidence interval [CI], 0.61-0.73) was reached for the model with continuous variables and containing all biomarkers. The calibration plots are presented in - Fig. 1. Visual inspection shows that the calibration plots closely follow the $45^{\circ}$ degree line thereby indicating good calibration. - Table 3 shows model characteristics for several cut-off values of predictive probabilities for PTS. Efficiency of the models can be read from the table by dividing the denominator found in the column $N$ under negative predictive value, by $N$ for the corresponding model. For example, at a threshold of $15 \%, 146$ out of 451 (32.4\%) are allocated to a low risk for PTS and might be excluded from extra interventions, at the cost of $9.9 \%$ missed PTS.

- Table 4 presents the simplified clinical risk scores for the baseline and secondary model with PTS. A score of $\leq 2$ points is associated with a $10 \%$ risk for the development of PTS, a score of 3 or 4 points indicates a risk of $20 \%$ and a score of $\geq 5$ points is associated with a risk of $40 \%$. The AUC of the models with the clinical risk scores equalled 0.73 (95\% CI, $0.67-0.78$ ) for the baseline model and 0.62 (95\% CI, 0.550.68 ) for the secondary model.

\section{External Validation}

The occurrence of PTS at 6 months in the validation cohort was $20.6 \%$ and in the following 18 months another $22.4 \%$ of
Table 2 Prediction model for post-thrombotic syndrome

\begin{tabular}{|c|c|c|c|}
\hline \multirow[b]{2}{*}{ Variable } & \multicolumn{2}{|l|}{ Initial model } & \multirow{2}{*}{$\begin{array}{l}\begin{array}{l}\text { Internally } \\
\text { validated } \\
\text { model }\end{array} \\
\begin{array}{l}\text { Regression } \\
\text { coefficient }^{\mathrm{a}}\end{array}\end{array}$} \\
\hline & $\begin{array}{l}\text { Regression } \\
\text { coefficient }\end{array}$ & $\begin{array}{l}\text { OR } \\
(95 \% \mathrm{Cl})\end{array}$ & \\
\hline \multicolumn{4}{|l|}{ Baseline model } \\
\hline Intercept & -2.593 & - & -2.428 \\
\hline Age $>56$ & 0.779 & $\begin{array}{l}2.18 \\
(1.30-3.66)\end{array}$ & 0.694 \\
\hline $\begin{array}{l}\text { Body mass } \\
\text { index }>30\end{array}$ & 0.801 & $\begin{array}{l}2.22 \\
(1.36-3.66)\end{array}$ & 0.713 \\
\hline Varicose veins & 1.505 & $\begin{array}{l}4.50 \\
(2.51-8.08)\end{array}$ & 1.339 \\
\hline Smoking & 0.551 & $\begin{array}{l}1.74 \\
(1.01-3.03)\end{array}$ & 0.490 \\
\hline History of DVT & 0.573 & $\begin{array}{l}1.77 \\
(1.01-3.11)\end{array}$ & 0.510 \\
\hline Male sex & -0.429 & $\begin{array}{l}0.65 \\
(0.39-1.08)\end{array}$ & -0.382 \\
\hline $\begin{array}{l}\text { Iliofemoral } \\
\text { thrombosis }\end{array}$ & 0.556 & $\begin{array}{l}1.74 \\
(0.99-3.06)\end{array}$ & 0.495 \\
\hline Provoked DVT & 0.345 & $\begin{array}{l}1.41 \\
(0.84-2.37)\end{array}$ & 0.307 \\
\hline \multicolumn{4}{|l|}{$\begin{array}{l}\text { Secondary } \\
\text { model }\end{array}$} \\
\hline Intercept & -1.521 & - & -1.393 \\
\hline Age $>56$ & 0.369 & $\begin{array}{l}1.45 \\
(0.89-2.35)\end{array}$ & 0.299 \\
\hline $\begin{array}{l}\text { Body mass } \\
\text { index }>30\end{array}$ & 0.391 & $\begin{array}{l}1.48 \\
(0.87-2.53)\end{array}$ & 0.317 \\
\hline Varicose veins & 1.032 & $\begin{array}{l}2.81 \\
(1.36-5.80)\end{array}$ & 0.836 \\
\hline Smoking & 0.477 & $\begin{array}{l}1.61 \\
(0.91-2.84)\end{array}$ & 0.387 \\
\hline $\begin{array}{l}\text { Residual vein } \\
\text { obstruction }\end{array}$ & 0.342 & $\begin{array}{l}1.41 \\
(0.86-2.31)\end{array}$ & 0.277 \\
\hline History of DVT & & & - \\
\hline Male sex & - & - & - \\
\hline $\begin{array}{l}\text { Iliofemoral } \\
\text { thrombosis }\end{array}$ & - & - & - \\
\hline $\begin{array}{l}\text { Provoked } \\
\text { DVT }\end{array}$ & - & - & - \\
\hline
\end{tabular}

Abbreviations: $\mathrm{Cl}$, confidence interval; DVT, deep vein thrombosis; OR, odds ratio.

${ }^{a}$ Multiplied by shrinkage factor ( 0.86 for the baseline and 0.81 for the second model) to adjust for over-fitting.

the remaining patients developed PTS. Validation of the simplified clinical risk scores without one predictor (smoking status) showed an AUC of 0.66 (95\% CI, 0.63-0.70) for the baseline model and 0.64 (95\% CI, 0.60-0.69) for the secondary model. 


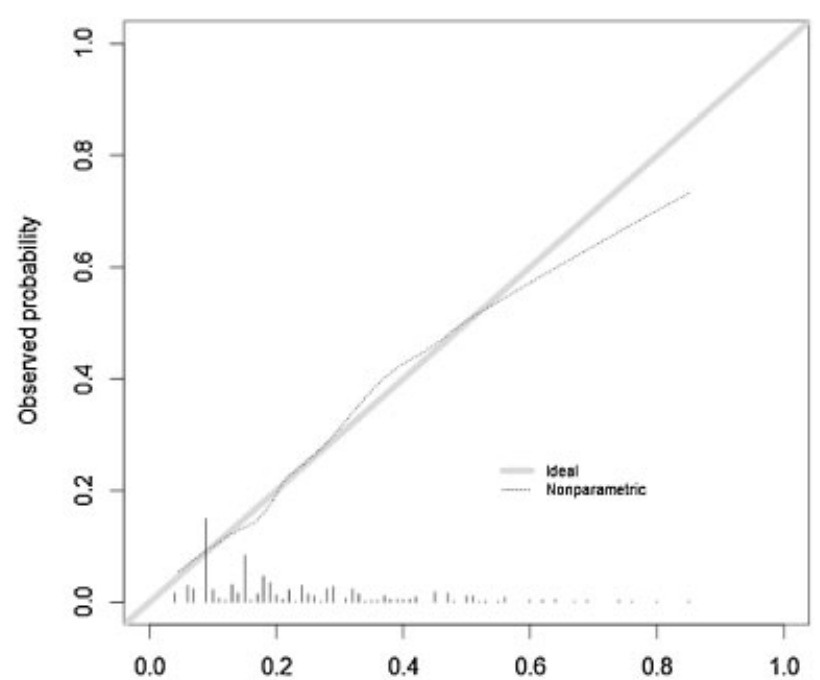

A

Fig. 1 The calibration plots of the baseline model (A) and the secondary model (B) for post-thrombotic syndrome.

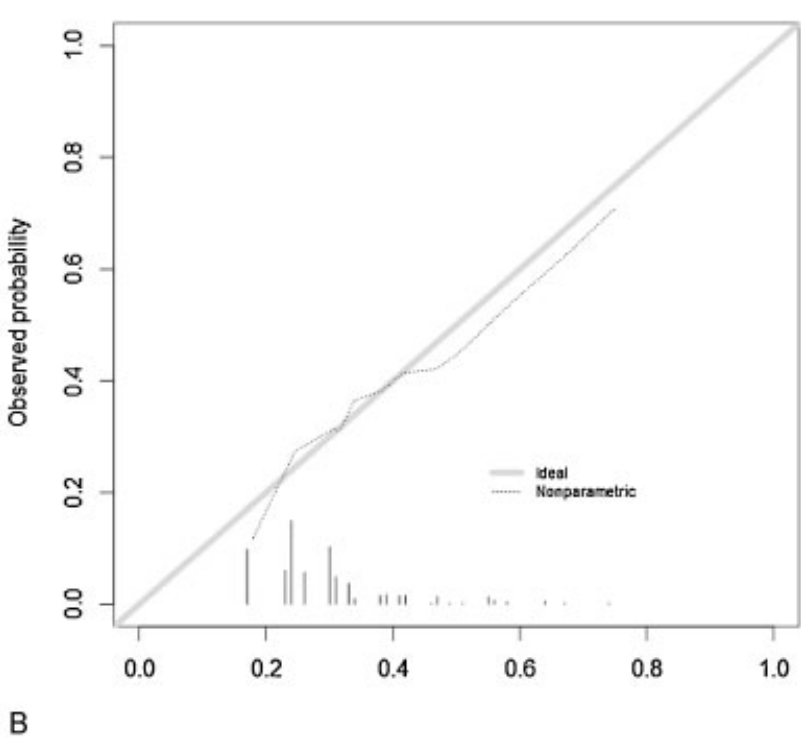

\section{Discussion}

We developed a baseline prediction model (clinical risk score) for PTS that is practical and easy to use. The model has good predictive performance with an AUC of 0.71 and an AUC of 0.73 for the derived risk score. Risk assessment can be performed in the acute phase as soon as the patient is diagnosed with DVT, and is based on only those variables that are readily available at baseline. The secondary model and clinical risk score can subsequently be applied in the subacute phase ( 6 months after venous thrombosis) and could be used to identify those patients that may either stop preventive therapy or are in need of continued or adjunctive therapy. The secondary prediction model discriminates moderately between patients at high risk and low risk for PTS with AUCs of 0.60 (AUC clinical risk score, 0.62). The addition of biomarkers did not improve the models' discriminative ability and had overall very little influence on the results. This might be due to the fact that the biomarkers available from the derivation cohort were measured in the chronic phase of DVT. It could therefore very well be that biomarkers measured in the acute phase of DVT may have additional predictive value and might thereby improve the models' performance. ${ }^{32}$

The efficiency of the models was the greatest for the baseline model at a threshold of $15 \%$ in which $32.4 \%$ of patients are classified as low risk at the cost of $9.9 \%$ missed cases. In previously published studies, margins set even as high as $10 \%$ were deemed acceptable. ${ }^{33}$ It needs, however, to be determined which threshold is more desirable both from a medical perspective (accurate identification of patients at risk for PTS) and which is more desirable from a societal perspective (most efficient selection of patients that can be excluded from further treatment). It would require decision analytical modelling to compare the savings associated with the treatment of fewer patients, to the health benefits forgone associated with the percentage of patient that was erroneously left untreated.

Validation of the baseline and secondary clinical risk scores in a new large set of patients in which the predictor smoking status was absent, showed to be successful. The baseline risk score corresponded to an AUC of 0.66 and the secondary risk score showed an AUC of 0.64, which was slightly better than in the derivation cohort. This indicates that the risk scores could also be applied to other patient populations with thrombosis. To our knowledge no externally validated prediction models for PTS exist so far, therefore comparison is not possible. At the end of November 2017, one study on the development of a prediction model for PTS has been published. ${ }^{34}$ The study used data from a randomized controlled trial that compared the effect of elastic compression stockings to placebo stockings for prevention of PTS in patients with proximal DVT. Because the prediction model was developed in a trial with several inclusion and exclusion criteria, and the diagnosis of PTS was based on the Ginsberg criteria rather than the current consensus-supported Villalta score, it is not likely that the model could be readily applied to all patients with DVT. Moreover, this prediction model has not yet been externally validated. Consequently, it is not directly suitable for clinical use.

The most important limitation for the development of the models was the lack of gold standard for PTS. Another limitation is that biomarkers were measured at a later stage after DVT and that no biomarkers were available for the acute phase of DVT. Inflammatory markers in the acute phase might have offered better predictive value for PTS and thereby have increased the discriminative ability of our models. The strength of our models and 
Table 3 Model characteristics

\begin{tabular}{|c|c|c|c|c|c|c|c|c|}
\hline \multirow[t]{3}{*}{ Threshold } & & & & & & & & \\
\hline & \multicolumn{2}{|c|}{ Sensitivity } & \multicolumn{2}{|c|}{ Specificity } & \multicolumn{2}{|c|}{ Positive predictive value } & \multicolumn{2}{|c|}{$\begin{array}{l}\text { Negative predictive } \\
\text { value }\end{array}$} \\
\hline & $N$ & $\%$ & $N$ & $\%$ & $N$ & $\%$ & $N$ & $\%$ \\
\hline \multicolumn{9}{|c|}{ Baseline model $(N=451)$} \\
\hline 2.5 & $103 / 103$ & 100 & - & - & $103 / 451$ & 22.8 & - & - \\
\hline 5 & $103 / 103$ & 100 & $9 / 348$ & 2.6 & $103 / 442$ & 23.3 & $9 / 9$ & 100 \\
\hline 7.5 & $103 / 103$ & 100 & $25 / 348$ & 7.2 & $103 / 426$ & 24.2 & $25 / 25$ & 100 \\
\hline 10 & $91 / 103$ & 88.3 & $106 / 348$ & 30.5 & $91 / 333$ & 27.3 & $106 / 118$ & 89.8 \\
\hline 12.5 & $90 / 103$ & 87.4 & $121 / 348$ & 34.8 & $90 / 317$ & 28.4 & $121 / 134$ & 90.3 \\
\hline 15 & $87 / 103$ & 84.5 & $146 / 348$ & 42.0 & $87 / 289$ & 30.1 & $146 / 162$ & 90.1 \\
\hline 17.5 & $78 / 103$ & 75.7 & $191 / 348$ & 54.9 & $78 / 235$ & 33.2 & $191 / 216$ & 88.4 \\
\hline 20 & $73 / 103$ & 70.9 & $231 / 348$ & 66.4 & $73 / 190$ & 38.4 & $231 / 261$ & 88.5 \\
\hline 22.5 & $70 / 103$ & 68.0 & $249 / 348$ & 71.6 & $70 / 169$ & 41.4 & $249 / 282$ & 88.3 \\
\hline 25 & $63 / 103$ & 61.2 & $260 / 348$ & 74.7 & $63 / 151$ & 41.7 & $260 / 300$ & 86.7 \\
\hline \multicolumn{9}{|c|}{ Secondary model $(N=301)$} \\
\hline 2.5 & $103 / 103$ & 100 & - & - & $103 / 348$ & 29.6 & - & - \\
\hline 5 & $103 / 103$ & 100 & - & - & $103 / 348$ & 29.6 & - & - \\
\hline 7.5 & $103 / 103$ & 100 & - & - & $103 / 348$ & 29.6 & - & - \\
\hline 10 & $103 / 103$ & 100 & - & - & $103 / 348$ & 29.6 & - & - \\
\hline 12.5 & $103 / 103$ & 100 & - & - & $103 / 348$ & 29.6 & - & - \\
\hline 15 & $103 / 103$ & 100 & - & - & $103 / 348$ & 29.6 & - & - \\
\hline 17.5 & $103 / 103$ & 100 & - & - & $103 / 348$ & 29.6 & - & - \\
\hline 20 & $97 / 103$ & 94.2 & $44 / 245$ & 18.0 & $97 / 298$ & 32.6 & $44 / 50$ & 88.0 \\
\hline 22.5 & $97 / 103$ & 94.2 & $44 / 245$ & 18.0 & $97 / 298$ & 32.6 & $44 / 50$ & 88.0 \\
\hline 25 & $70 / 103$ & 68.0 & $124 / 245$ & 50.6 & $70 / 191$ & 36.6 & $124 / 157$ & 79.0 \\
\hline
\end{tabular}

Table 4 Clinical risk scores for post-thrombotic syndrome

\begin{tabular}{|l|l|l|}
\hline & $\begin{array}{l}\text { Baseline risk } \\
\text { assessment }\end{array}$ & $\begin{array}{l}\text { Risk } \\
\text { assessment } \\
\text { in the } \\
\text { sub-acute } \\
\text { phase }\end{array}$ \\
\hline Variable & & \\
\hline Age $>56$ & 2 & 1 \\
\hline Body mass index $>30$ & 2 & 1 \\
\hline Varicose veins & 4 & 3 \\
\hline Smoking & 1 & 1 \\
\hline Residual vein obstruction & - & 1 \\
\hline Female sex & 1 & - \\
\hline $\begin{array}{l}\text { Provoked deep vein } \\
\text { thrombosis }\end{array}$ & 1 & - \\
\hline Iliofemoral thrombosis & 1 & - \\
\hline $\begin{array}{l}\text { History of deep vein } \\
\text { thrombosis }\end{array}$ & 1 & - \\
\hline
\end{tabular}

Note: Risk of post-thrombotic syndrome development: Baseline model: Score $0-2$ points, $10 \%$; $3-4$ points, $20 \%$; $\geq 5$ points, $40 \%$. Secondary model: Score $0-2$ points, $25 \%$; $3-4$ points, $45 \%$; $>5$ points $60 \%$.

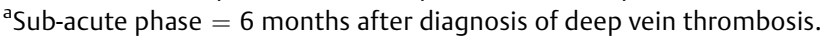

clinical risk scores is that they are derived from a cohort of patients with DVT in which all consecutive patients were included; this will likely increase the generalizability of the models as was shown in the external validation phase. Another strength is the simplicity of the models/ risk scores. The application of the baseline model is anticipated to be easy because the predictors are dichotomized and are commonly available at baseline, so this model can be used at no additional costs since no expensive diagnostic measurements are required. Even for the secondary model costs are expected to be moderate, as only the additional assessment of residual vein obstruction is needed.

Our two-step model has the potential to both improve patient care and at the same time reduce costs. At time of DVT diagnosis, based on readily accessible baseline clinical characteristics, clinicians can predict the individual patients' risk for developing PTS at 6 months after DVT. In the sub-acute phase, the individual risk can be estimated with the additional assessment of residual thrombosis. Therapy can thus be allocated to those who will likely benefit the most, which could also result in a better cost-effectiveness balance. 


\section{What is known about this topic?}

- Post-thrombotic syndrome is a common chronic consequence of deep vein thrombosis that affects the quality of life to great extent and is associated with substantial costs.

- Thus far in the clinic, it is not possible to predict the individual risk of post-thrombotic syndrome in patients with deep vein thrombosis.

\section{What does this paper add?}

- A newly developed and externally validated easily applicable two-step prediction model and its corresponding risk score, could serve as a tool for identifying patients at risk of post-thrombotic syndrome.

- Consequently, preventive therapy in the acute and sub-acute phase of deep vein thrombosis can be individually tailored.

Ethical Approval

For this study, no separate ethical approval was needed or acquired, but data from the clinical care pathway in MUMC+ was used. For data collection in this pathway, approval was obtained by Maastricht University Medical Centre Ethics Committee (reference METC 15-4-256). No informed consent from participants was required.

\section{Funding}

None.

\section{Conflict of Interest}

None.

\section{References}

1 Brandjes DP, Büller HR, Heijboer H, et al. Randomised trial of effect of compression stockings in patients with symptomatic proximalvein thrombosis. Lancet 1997;349(9054):759-762

2 Prandoni P, Lensing AW, Cogo A, et al. The long-term clinical course of acute deep venous thrombosis. Ann Intern Med 1996; 125(01):1-7

3 Kahn SR, Shrier I, Julian JA, et al. Determinants and time course of the postthrombotic syndrome after acute deep venous thrombosis. Ann Intern Med 2008;149(10):698-707

4 Guanella R, Ducruet T, Johri M, et al. Economic burden and cost determinants of deep vein thrombosis during 2 years following diagnosis: a prospective evaluation. J Thromb Haemost 2011;9 (12):2397-2405

5 Prandoni P, Lensing AW, Prins MH, et al. Below-knee elastic compression stockings to prevent the post-thrombotic syndrome: a randomized, controlled trial. Ann Intern Med 2004; 141(04):249-256

6 van Dongen CJ, Prandoni P, Frulla M, Marchiori A, Prins MH, Hutten BA. Relation between quality of anticoagulant treatment and the development of the postthrombotic syndrome. J Thromb Haemost 2005;3(05):939-942

7 Chitsike RS, Rodger MA, Kovacs MJ, et al. Risk of post-thrombotic syndrome after subtherapeutic warfarin anticoagulation for a first unprovoked deep vein thrombosis: results from the REVERSE study. J Thromb Haemost 2012;10(10):2039-2044
8 Stain M, Schönauer V, Minar E, et al. The post-thrombotic syndrome: risk factors and impact on the course of thrombotic disease. J Thromb Haemost 2005;3(12):2671-2676

9 Tick LW, Kramer MH, Rosendaal FR, Faber WR, Doggen CJ. Risk factors for post-thrombotic syndrome in patients with a first deep venous thrombosis. J Thromb Haemost 2008;6(12):2075-2081

10 Ageno W, Piantanida E, Dentali F, et al. Body mass index is associated with the development of the post-thrombotic syndrome. Thromb Haemost 2003;89(02):305-309

11 Ten Cate-Hoek AJ, Ten Cate H, Tordoir J, Hamulyák K, Prins MH. Individually tailored duration of elastic compression therapy in relation to incidence of the postthrombotic syndrome. J Vasc Surg 2010;52(01):132-138

12 Prandoni P, Frulla M, Sartor D, Concolato A, Girolami A. Vein abnormalities and the post-thrombotic syndrome. J Thromb Haemost 2005;3(02):401-402

13 Latella J, Desmarais S, Miron MJ, et al. Relation between D-dimer level, venous valvular reflux and the development of post-thrombotic syndrome after deep vein thrombosis. J Thromb Haemost 2010;8(10):2169-2175

14 Bouman AC, Smits JJ, Ten Cate H, Ten Cate-Hoek AJ. Markers of coagulation, fibrinolysis and inflammation in relation to post-thrombotic syndrome. J Thromb Haemost 2012;10(08): 1532-1538

15 Rabinovich A, Cohen JM, Cushman M, et al. Inflammation markers and their trajectories after deep vein thrombosis in relation to risk of post-thrombotic syndrome. J Thromb Haemost 2015;13(03): 398-408

16 Ziegler S, Schillinger M, Maca TH, Minar E. Post-thrombotic syndrome after primary event of deep venous thrombosis 10 to 20 years ago. Thromb Res 2001;101(02):23-33

17 Villalta S, Bagatella P, Piccioli A, Lensing A, Prins MH, Prandoni P. Assessment of validity and reproducibility of a clinical scale for the post-thrombotic syndrome. Haemostasis 1994;24(158a)

18 Kearon C, Kahn SR, Agnelli G, Goldhaber S, Raskob GE, Comerota AJ. Antithrombotic therapy for venous thromboembolic disease: American College of Chest Physicians Evidence-Based Clinical Practice Guidelines (8th Edition). Chest 2008;133(6 Suppl):454S-545S

19 Ginsberg JS, Hirsh J, Julian J, et al. Prevention and treatment of postphlebitic syndrome: results of a 3-part study. Arch Intern Med 2001;161(17):2105-2109

20 Appelen D, van Loo E, Prins MH, Neumann MH, Kolbach DN. Compression therapy for prevention of post-thrombotic syndrome. Cochrane Database Syst Rev 2017;9:CD004174

21 Padberg FT Jr, Johnston MV, Sisto SA. Structured exercise improves calf muscle pump function in chronic venous insufficiency: a randomized trial. J Vasc Surg 2004;39(01):79-87

22 O'Donnell MJ, McRae S, Kahn SR, et al. Evaluation of a venousreturn assist device to treat severe post-thrombotic syndrome (VENOPTS). A randomized controlled trial. Thromb Haemost 2008;99(03):623-629

23 Ippolito E, Belcaro G, Dugall M, et al. Venoruton®: post thrombotic syndrome. Clinical improvement in venous insufficiency (signs and symptoms) with Venoruton ${ }^{\circledR}$. A five-year, open-registry, efficacy study. Panminerva Med 2011;53(03, Suppl 1):13-19

24 Kahn SR, Shrier I, Shapiro S, et al. Six-month exercise training program to treat post-thrombotic syndrome: a randomized controlled two-centre trial. CMAJ 2011;183(01):37-44

25 Haig Y, Enden T, Grøtta O, et al; CaVenT Study Group. Postthrombotic syndrome after catheter-directed thrombolysis for deep vein thrombosis (CaVenT): 5 -year follow-up results of an open-label, randomised controlled trial. Lancet Haematol 2016;3 (02):e64-e71

26 Vedantham S, Goldhaber SZ, Julian JA, et al; ATTRACT Trial Investigators. Pharmacomechanical catheter-directed thrombolysis for deep-vein thrombosis. N Engl J Med 2017;377(23):2240-2252

27 Peduzzi P, Concato J, Kemper E, Holford TR, Feinstein AR. A simulation study of the number of events per variable in 
logistic regression analysis. J Clin Epidemiol 1996;49(12): 1373-1379

28 Kahn SR, Partsch H, Vedantham S, Prandoni P, Kearon C; Subcommittee on Control of Anticoagulation of the Scientific and Standardization Committee of the International Society on Thrombosis and Haemostasis. Definition of post-thrombotic syndrome of the leg for use in clinical investigations: a recommendation for standardization. J Thromb Haemost 2009;7(05):879-883

29 van Kuijk SMJ, Viegtbauer W, Peeters LL, Smits L. Bias in regression coefficient estimates when assumptions for handling missing data are violated: a simulation study. Epidemiol Biostat Public Health 2016;13(01):e11598

30 Steyerberg EW. Clinical Prediction Models: A Practical Approach to Development, Validation, and Updating. New York: SpringerVerlag; 2009
31 Collins GS, Reitsma JB, Altman DG, Moons KG. Transparent reporting of a multivariable prediction model for individual prognosis or diagnosis (TRIPOD): the TRIPOD statement. BMJ 2015;350:g7594

32 Ten Cate-Hoek AJ, Henke PK, Wakefield TW. The post thrombotic syndrome: ignore it and it will come back to bite you. Blood Rev 2016;30(02):131-137

33 Kahn SR, Shapiro S, Wells PS, et al; SOX trial investigators. Compression stockings to prevent post-thrombotic syndrome: a randomised placebo-controlled trial. Lancet 2014;383 (9920):880-888

34 Rabinovich A, Ducruet T, Kahn SR. Development of a clinical prediction model for the postthrombotic syndrome in a prospective cohort of patients with proximal deep vein thrombosis. J Thromb Haemost 2018;16(02):262-270 